\title{
Analysis of postmortem metabolic changes in rat kidney cortex using Fourier transform infrared spectroscopy
}

\author{
Ping Huang ${ }^{\mathrm{a}}$, Yong Ke ${ }^{\mathrm{a}}$, Qinyang $\mathrm{Lu}^{\mathrm{a}}$, Bo Xin ${ }^{\mathrm{a}}$, Shuanliang Fan ${ }^{\mathrm{a}}$, Guangde Yang ${ }^{\mathrm{b}}$ and \\ Zhenyuan Wang ${ }^{\mathrm{a}, *}$ \\ ${ }^{a}$ Department of Forensic Medicine, School of Medicine, Xi'an Jiaotong University, Xi'an, P. R. China \\ ${ }^{\mathrm{b}}$ Institute of Chemical Analysis Research, Xi'an Jiaotong University, Xi'an, P. R. China
}

\begin{abstract}
Estimation of the time since death (postmortem interval, PMI) is one of the most difficult problems in forensic investigations and many methods currently are utilized to estimate the PMI. The aim of this study was to investigate the changes of Fourier transform infrared (FT-IR) spectra of rat kidney cortex from time zero to $168 \mathrm{~h}$ postmortem at molecular level. The spectra of rat kidney cortex displayed the prominent changes with increasing postmortem interval. (1) Significant increase in the intensity of the C-H stretching bands at $2958,2925,2871,2852 \mathrm{~cm}^{-1}$, the $=\mathrm{C}-\mathrm{H}$ stretching band at $3012 \mathrm{~cm}^{-1}$, the $\mathrm{CO}_{2}{ }^{-}$symmetric stretching band at $1396 \mathrm{~cm}^{-1}$ and the $\mathrm{N}-\mathrm{H}$ bend, $\mathrm{C}-\mathrm{N}$ stretching at $1541 \mathrm{~cm}^{-1}$; (2) significant decrease in the intensity of the $\mathrm{PO}_{2}{ }^{-}$stretching band at $1238,1080 \mathrm{~cm}^{-1}$; (3) the intensity of at 3303,1652 and $1170 \mathrm{~cm}^{-1}$ remained relatively stable. The linear regression analysis of the various absorption intensity and area ratios against the PMI shows a close correlation, maximum for $A_{1541} / A_{1396}$ ratio $\left(R^{2}=0.95\right)$ and minimum for $I_{1080} / I_{1396}$ ratio $\left(R^{2}=0.70\right)$. Our results indicate that FT-IR spectroscopy may be a useful technique for estimating the short- and long-term PMI.
\end{abstract}

Keywords: Postmortem interval, kidney cortex, Fourier transform infrared spectroscopy, linear regression

\section{Introduction}

The postmortem interval (PMI) refers to the time since death, and estimation of PMI is extremely important in criminal, civil and forensic investigations. An accurate determination of the PMI can help reconstruct a crime scene, differentiate between homicide and suicide, and pinpoint a suspect, etc. Many methods have been attempted to accurately determine the PMI. These include examination of external physical characteristics of the body, chemical changes of body fluids, stomach contents and cadaveric temperatures [1-7].

Following clinical death, a number of complicated chemical reactions continue to occur within cells due to the remaining functional enzymes. which may presumably cause specific time-dependent changes in metabolism and sub-cellular structures that may be used to determine PMI. Indeed, many sophisticated methods have been used to find reliable markers for the estimation of PMI, including the analysis of potassium concentration in vitreous humor [8-11] and postmortem protein degradation within different tissues [12,13]. In addition, some researches have been focused on the degradation of nucleic acid

\footnotetext{
*Corresponding author: Zhenyuan Wang, School of Medicine, Xi' an Jiaotong University, Xi' an 710061, P. R. China. Tel.: +8629 82655472; Fax: +8629 82655472; E-mail: wzy218@mail.xjtu.edu.cn.
} 
including DNA and RNA [14-16]. However, these methods require specialized laboratory analysis and sophisticated chemical procedures. It remains a challenge for forensic scholars to look for simpler and more efficient methods to determine PMI.

Fourier transform infrared (FT-IR) spectroscopy has become an increasingly powerful analytical tool in biochemistry, biophysics, biomedicine and molecular biology due to its high sensitivity in detecting the changes in the functional groups belonging to tissue components, such as proteins, lipids, nucleic acids and carbohydrates, etc. In recent years, the quantitative analysis using FT-IR spectroscopy has been used in many scientific fields, such as the environmental detection, the diagnosis of cancers and other disorders [17-24].

The FT-IR spectroscopy is a non-chemical procedure as opposed to other bio-molecular methods that may influence the chemical reaction within the postmortem tissues. In the present study, we investigated the postmortem changes on an experimental animal model. The rat kidney cortex was investigated at the molecular level by detecting the different functional groups using FT-IR spectroscopy. The kidney cortex tissue was selected due to be autolysis easily based on the histological observation. The enzymes in kidney cortex tend to be more active and putrefaction occurs early. The correlation between the different intensity and area ratios and the PMI was investigated using linear regression analyses based on FT-IR data, which to our knowledge, has not been reported previously.

\section{Materials and methods}

\subsection{Animal specimens}

Male Sprague-Dawley rats $(n=10,240-260 \mathrm{~g})$ provided by the Animal Center of Xi' an Jiaotong University were sacrificed by cervical dislocation and the cadavers were kept in a controlled environment chamber set at $20( \pm 2)^{\circ} \mathrm{C}$. The kidney cortex were sub-sampled from the same rat at time zero, $12,24,48$, $72,96,120,144,168 \mathrm{~h}$ (9 readings in each of ten rats; $n=90)$. The kidney cortex was selected because the kidney cortex tends to be autolysis easily and earlier than other tissues based on the histological observation. The tissues were placed into $2.5 \mathrm{ml}$ cylindrical tubes and frozen immediately in liquid nitrogen. All of the animal experiments in the present study were performed in accordance with the principles for the Care and Use of Laboratory Animal Committee of Xi'an Jiaotong University.

\subsection{Sample preparation}

The tissues were freeze-dried in vacuo at $-50^{\circ} \mathrm{C} 12 \mathrm{~h}$ for dehydration. About $2 \mathrm{mg}$ of freeze-dried tissue was mixed with $200 \mathrm{mg}$ of $\mathrm{KBr}$, ground with an agate mortar and pestle for $5 \mathrm{~min}$ and then pressed into a pellet for $1 \mathrm{~min}$ using a force of 10 tons. The measured thickness of the pellets was $0.4 \mathrm{~mm}$ and the diameter was $12 \mathrm{~mm}$.

\subsection{FT-IR spectral measurement}

The FT-IR spectra were recorded quantitatively at room temperature in the range $4000-400 \mathrm{~cm}^{-1}$ on a Shimadzu 8400S spectrometer. The spectrometer was kept on continuously to minimize warmup instability and was purged continuously with dry air to eliminate interference by atmospheric water vapor. Interferograms were averaged for 100 scans at $4 \mathrm{~cm}^{-1}$ resolution. IR solution 1.10 software (Shimadzu corporation, Japan) was used for analysis of the FT-IR spectra and for recording the data from 
the spectra (including the calculations of peak position, band intensity and area). Baseline correction was done for all the original spectra and $I_{x}$ represents the infrared absorption intensity at wave-number $x \mathrm{~cm}^{-1}$ and $A_{x}$ represent the infrared absorption area at wave-number $x \mathrm{~cm}^{-1}$.

\subsection{Statistical analysis}

Statistical analysis was conducted by evaluating the mean values of ratio of band intensity and area per sample. The experimental replicates were averaged and the mean values $\pm \mathrm{SD}$ was calculated for each time point. Linear regression analysis between band intensity and area ratios and PMI were performed. Linear regression analysis yielded the equations $(Y=A x+B)$ with a coefficient of determination $\left(R^{2}\right)$. $p$ values of less than 0.05 were regarded as being significant. All statistical analysis of the data was performed by using SPSS 11.5 software (SPSS Inc., USA).

\section{Results and discussion}

\subsection{General FT-IR findings}

The FT-IR original spectrum of rat kidney cortex were complex consisting of many bands arising from different functional groups belonging to lipids, carbohydrates, proteins, and nucleic acids. Moreover, the biological tissues have a lot of different kinds of components including prenchymal, mesenchymal, and blood. So FT-IR spectra of the kidney cortex are delivering sum spectra of these components. The 16 major absorption bands were elicited for analyzing the changes of chemical functions. To normalize the quantitative analysis of absorption bands, the intensity and area ratios of the different absorption bands were considered.

The detailed spectra analysis were performed in three distinct frequency ranges, namely between $3600-2800,1700-1375,1300-900 \mathrm{~cm}^{-1}$. The enlarged original spectra at different time point from 0 to $168 \mathrm{~h}$ postmortem in the $3600-2800,1700-1375,1300-900 \mathrm{~cm}^{-1}$ were plotted together in Fig. 1 . The 16 major bands were selected and assigned in Table 1. As demonstrated in Fig. 2, four full complete FTIR spectra showed the changes of the 16 major bands at $0,24,72$ and $168 \mathrm{~h}$ postmortem. The intensity or accurately the area of the absorption bands is directly related to the concentration of the molecules [19, $20,22,25]$. Furthermore, the mean values $( \pm S D)$ of band intensity and area ratios, derived from all of the ten cadavers, at each time point postmortem were shown in Figs 3-5. The linear regression correlations of the intensity and area ratios against PMI were plotted by the dotted lines in Figs 3-5. The linear regression equations of the different intensity and area ratios were demonstrated in Table 2 . The peak position of 16 absorption bands remained relatively stable in their own stretching ranges from $0 \mathrm{~h}$ to $168 \mathrm{~h}$ postmortem.

\subsection{The absorption band region at $3600-2800 \mathrm{~cm}^{-1}$}

As shown in Fig. 1(a), the region of 3600-2800 $\mathrm{cm}^{-1}$ presented 6 major absorption bands at 3303, $3012,2958,2925,2871,2852 \mathrm{~cm}^{-1}$. The intensity of the band at $3303 \mathrm{~cm}^{-1}$ remained stable, which contains a strong absorption arising mainly from the $\mathrm{N}-\mathrm{H}$ stretching (amide $\mathrm{A}$ ) mode of protein with the contribution of the $\mathrm{OH}$ stretching modes in $\mathrm{H}_{2} \mathrm{O}$, polysaccharides $[17,20]$. As it can be seen from Fig. 1(a) and Fig. 2, there was a dramatic increase in this region whose spectrum is populated by absorptions stemming from the $\mathrm{C}-\mathrm{H}$ stretching vibrations of olefinic $=\mathrm{CH},-\mathrm{CH}_{2}$ and $-\mathrm{CH}_{3}$ groups $[18,19,23,25]$. 


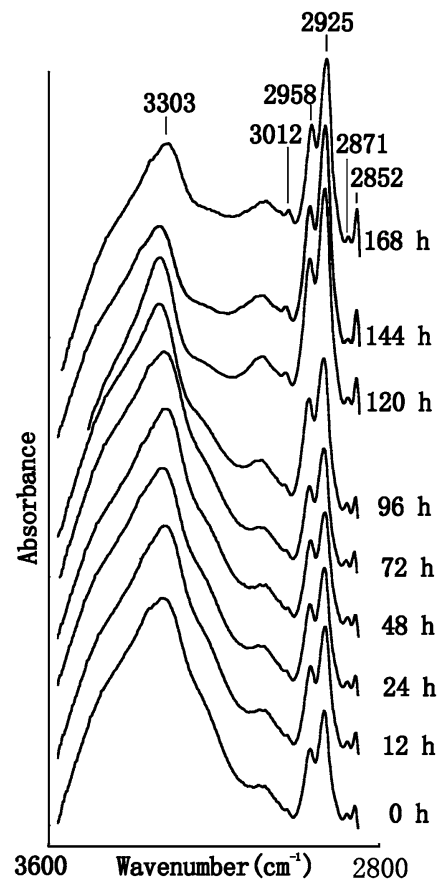

(a)

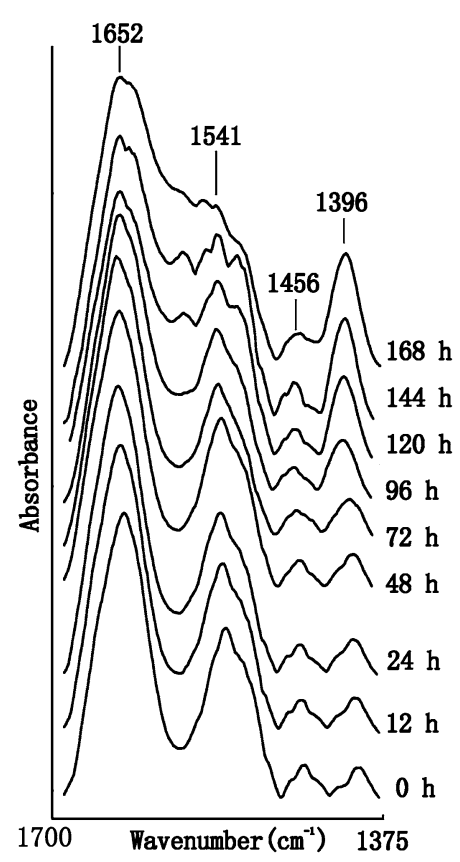

(b)

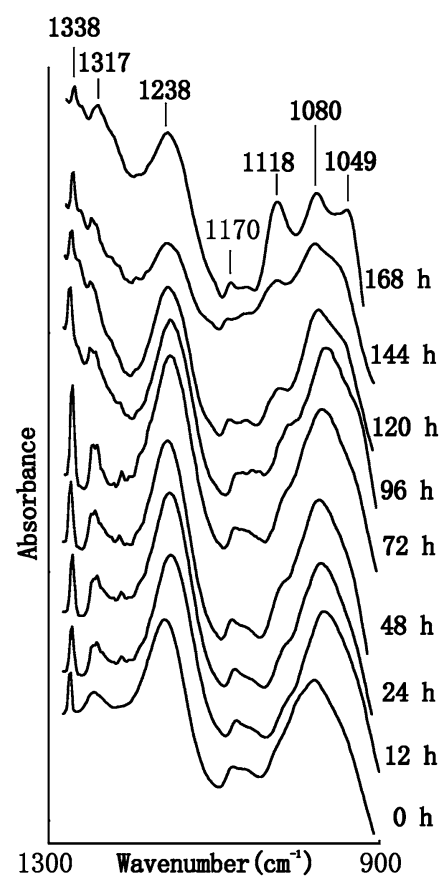

(c)

Fig. 1. Time-course of enlarged FT-IR original spectra from 0 to $168 \mathrm{~h}$ postmortem in rat kidney cortex at $20^{\circ} \mathrm{C}$. (a) $3600-2800 \mathrm{~cm}^{-1}$ region; (b) $1700-1375 \mathrm{~cm}^{-1}$ region; (c) $1300-900 \mathrm{~cm}^{-1}$ region.

Table 1

Major absorption in the FTIR spectra of rat kidney cortex

\begin{tabular}{|c|c|c|c|}
\hline Band numbers & Range $\left(\mathrm{cm}^{-1}\right)$ & Present position $\left(\mathrm{cm}^{-1}\right)$ & Assignments \\
\hline 1 & $3300-3500$ & 3303 & Maily N-H stretching (amide A) \\
\hline 2 & $3010-3014$ & 3012 & $=\mathrm{C}-\mathrm{H}$ stretching \\
\hline 3 & $2956-2960$ & 2958 & $\mathrm{CH}_{3}$ asymmetric stretching \\
\hline 4 & $2920-2925$ & 2925 & $\mathrm{CH}_{2}$ asymmetric stretching \\
\hline 5 & $2870-2876$ & 2871 & $\mathrm{CH}_{3}$ symmetric stretching \\
\hline 6 & $2850-2854$ & 2852 & $\mathrm{CH}_{2}$ symmetric stretching \\
\hline 7 & $1600-1690$ & 1652 & Amide $\mathrm{I}$ (protein $\mathrm{C}=\mathrm{O}$ stretching) \\
\hline 8 & $1480-1575$ & 1541 & Amide II (protein N-H bend, $\mathrm{C}-\mathrm{N}$ stretching) \\
\hline 9 & $1452-1458$ & 1454 & $\mathrm{CH}_{2}$ bending \\
\hline 10 & $1390-1400$ & 1396 & $\mathrm{CO}_{2}^{-}$symmetric stretching \\
\hline 11 & $1330-1340$ & 1338 & $\mathrm{CH}_{2}$ wagging stretching \\
\hline 12 & $1236-1240$ & 1238 & $\mathrm{PO}_{2}^{-}$asymmetric stretching \\
\hline 13 & $1150-1190$ & 1170 & $\mathrm{C}-\mathrm{OH}$ bending, $\mathrm{CO}-\mathrm{O}-\mathrm{C}$ asymmetric stretching \\
\hline 14 & $1118-1120$ & 1118 & Unconfirmed \\
\hline 15 & $1078-1083$ & 1080 & $\mathrm{PO}_{2}{ }^{-}$symmetric stretching \\
\hline 16 & $1029-1049$ & 1049 & $\mathrm{C}-\mathrm{O}$ stretching \\
\hline
\end{tabular}

Band assignment (see [20-29]). 


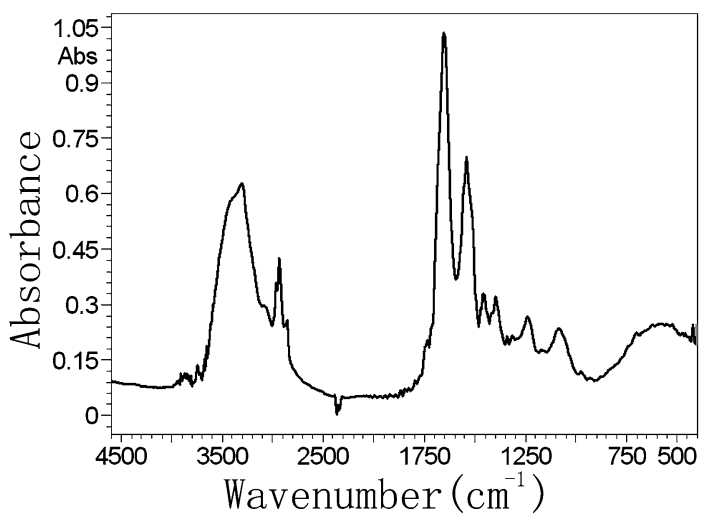

(a)

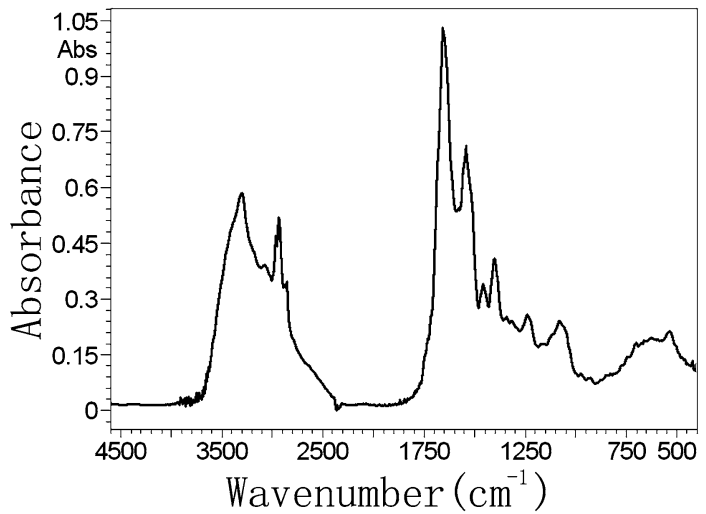

(c)

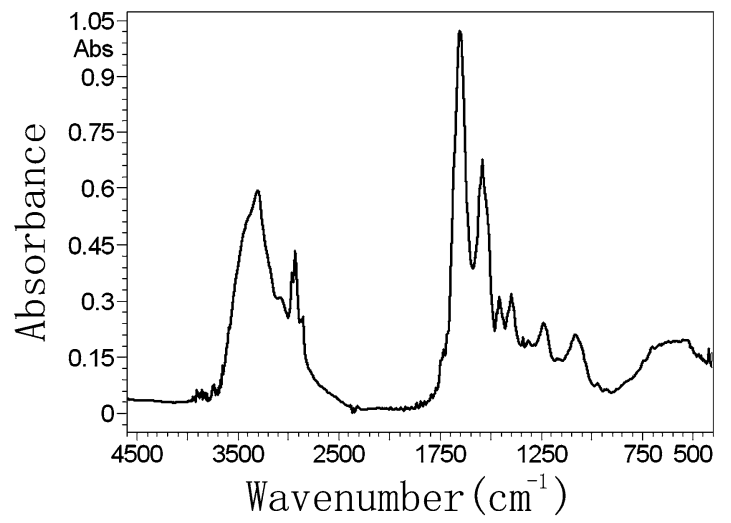

(b)

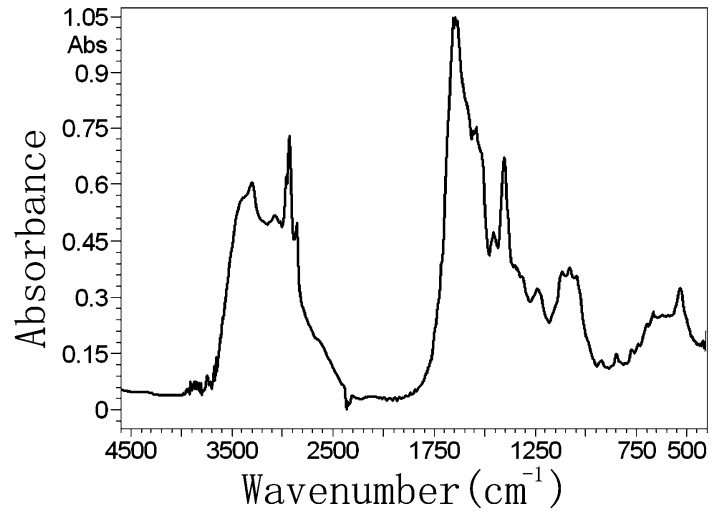

(d)

Fig. 2. Four complete FT-IR original spectra (a) $0 \mathrm{~h}$, (b) $24 \mathrm{~h}$, (c) $72 \mathrm{~h}$ and (d) $168 \mathrm{~h}$ postmortem.

As illustrated in Fig. 3(a)-(e), the $I_{3012} / I_{3303}, I_{2958} / I_{3303}, I_{2925} / I_{3303}, I_{2871} / I_{3303}, I_{2858} / I_{3303}$ ratios showed increase from $0 \mathrm{~h}$ to $168 \mathrm{~h}$ postmortem. However, the $I_{2958} / I_{3303}, I_{2925} / I_{3303}, I_{2871} / I_{3303}$ and $I_{2858} / I_{3303}$ ratios had the similar slight decrease at $72 \mathrm{~h}$ compared with $48 \mathrm{~h}$ and $96 \mathrm{~h}$. As demonstrated in Fig. 3(a)-(e), linear regression analysis showed strong correlations between the ratios and increasing time since death. Linear regression equations of the $I_{3012} / I_{3303}, I_{2958} / I_{3303}, I_{2925} / I_{3303}, I_{2871} / I_{3303}$, $I_{2858} / I_{3303}$ ratios against the PMI were shown in Table 2.

Our results show that all the ratios of $\mathrm{C}-\mathrm{H}$ to $\mathrm{N}-\mathrm{H}$ stretching bands increased significantly postmortem. The chemical mechanism underlying the specific changes is still unclear compared with the degradation of proteins and nucleic acids, because the chemical reactions in kidney cortex after death are so complex. However, the $\mathrm{C}-\mathrm{H}$ stretching groups in $3000-2800 \mathrm{~cm}^{-1}$ can serve as a marker for estimating PMI due to its sequential, time-dependent process.

\subsection{The absorption band region at $1700-1375 \mathrm{~cm}^{-1}$}

The bands at 1652 and $1541 \mathrm{~cm}^{-1}$ are attributed to amide I and amide II vibrations, respectively, of structural proteins $[18,26,27]$. The intensity of amide I remained stable, and the intensity of amide II increased postmortem. Figure 1(b) showed that there were some weak bands appearing around the band 


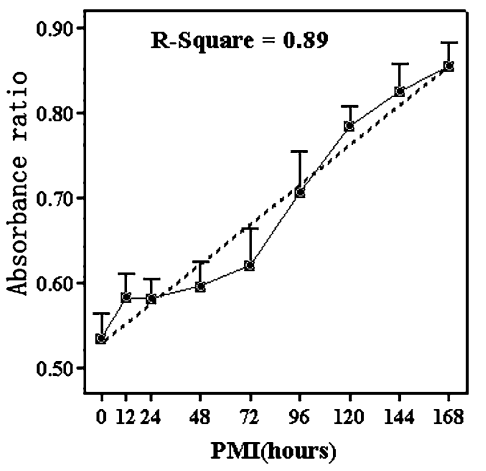

(a)

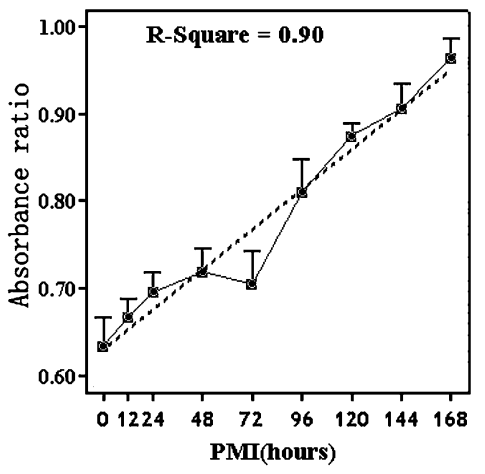

(b)

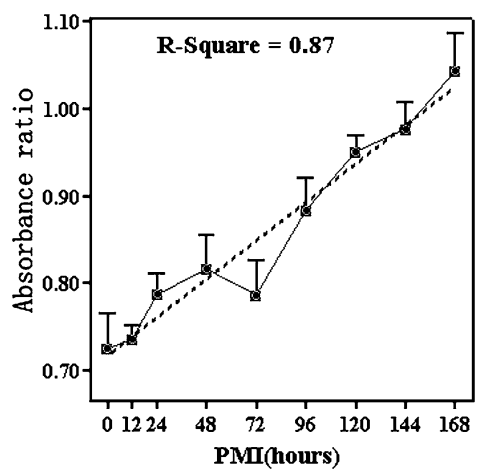

(c)

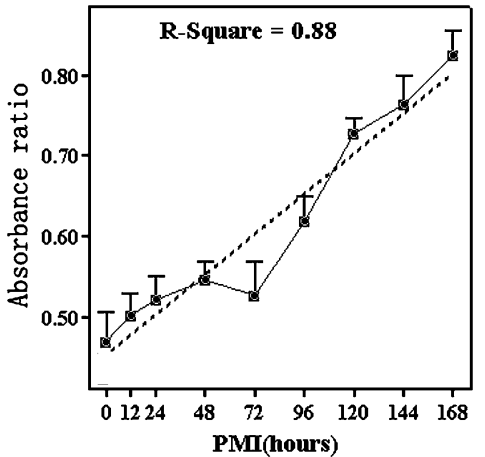

(d)

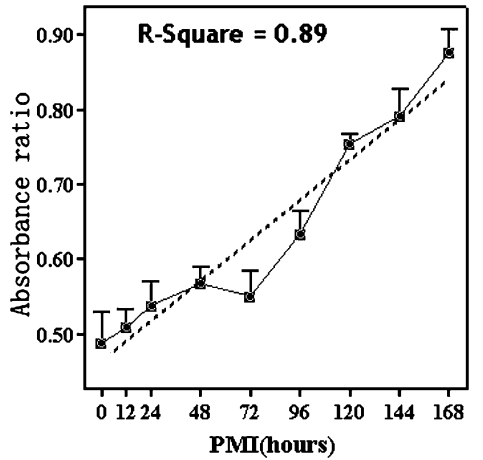

(e)

Fig. 3. Temporal FT-IR spectral intensity ratio of the bands (a) $I_{3012} / I_{3303}$, (b) $I_{2958} / I_{3303}$, (c) $I_{2925} / I_{3303}$, (d) $I_{2871} / I_{3303}$, (e) $I_{2858} / I_{3303}$. The fitting regression line (- - ) presented linear relationship between intensity ratio and PMI.

at $1541 \mathrm{~cm}^{-1}$ after $120 \mathrm{~h}$ postmortem in original spectra. We consider that the appearance of these weak absorption bands is closely related to increasing metabolites after death.

The band at $1456 \mathrm{~cm}^{-1}$, contributed by bending vibration of the $\mathrm{CH}_{2}$ in the lipids and proteins [25,27], slightly increased since death in the Figs 1 (b) and 2 . The bands at $1396 \mathrm{~cm}^{-1}$ is due to $\mathrm{CO}_{2}{ }^{-}$symmetric stretching vibration of amino acid side chains and fatty acids [23,28,29]. As shown in Figs 1(b) and 2, the intensity and area of this band increase dramatically. The $I_{1652} / I_{1396}, I_{1541} / I_{1396}$ and $I_{1456} / I_{1396}$ ratios (Fig. 4(a)-(c)) and the $A_{1652} / A_{1396}, A_{1541} / A_{1396}, A_{1456} / A_{1396}$ ratios (Fig. 4(d)-(f)) were used for the more precise quantitative analysis between the intensity and area ratios and the PMI. The band intensity and area ratios showed dramatic decrease with increasing time since death as shown in Fig. 4. The $A_{1652} / A_{1396}\left(R^{2}=0.94\right)$ and $A_{1541} / A_{1396}$ ratios $\left(R^{2}=0.95\right)$ showed strongest linear correlations among all the ratios. As shown in Fig. $4, I_{1652} / I_{1396}$ ratio appeared rather variable from $12 \mathrm{~h}$ to $72 \mathrm{~h}$ postmortem.

\subsection{The absorption band region at $1300-900 \mathrm{~cm}^{-1}$}

The bands at $1238,1080 \mathrm{~cm}^{-1}$ are mainly assigned to symmetric and asymmetric stretching modes, respectively, of phosphodiester groups in nucleic acids rather than in phospholipids [22,26,27]. As shown in Figs 1(c) and 2, the intensity at 1238, $1080 \mathrm{~cm}^{-1}$ displayed dramatic decrease with increasing time after death. The more precise changes for $1238,1080 \mathrm{~cm}^{-1}$ using the intensity bands ratios were displayed 


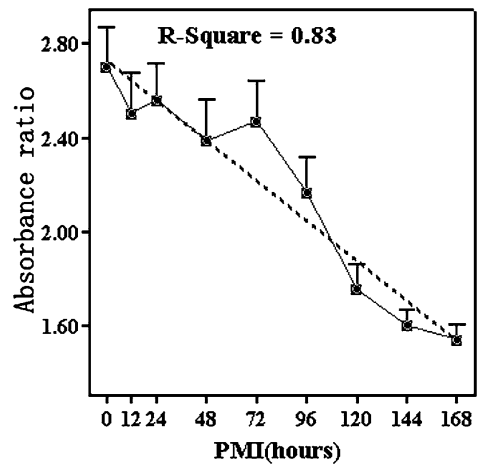

(a)

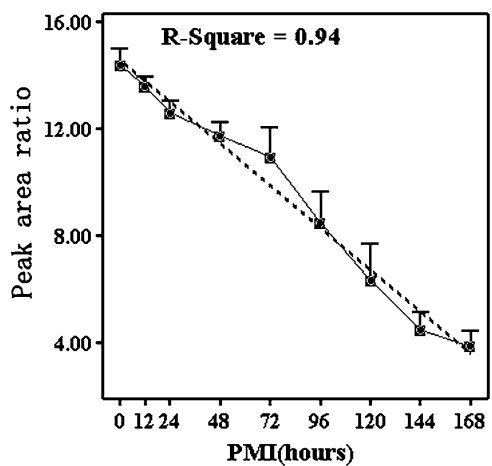

(d)

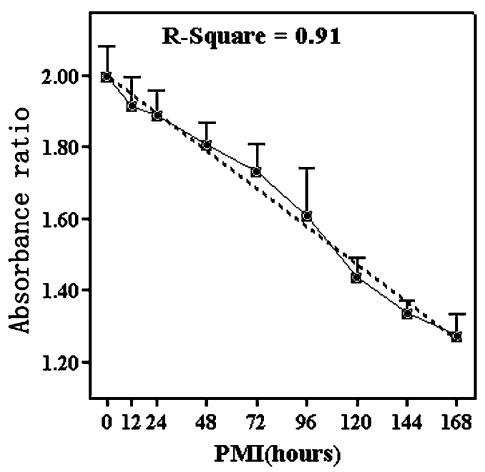

(b)

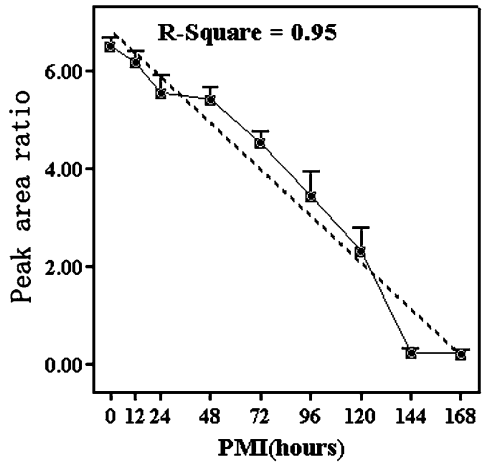

(e)

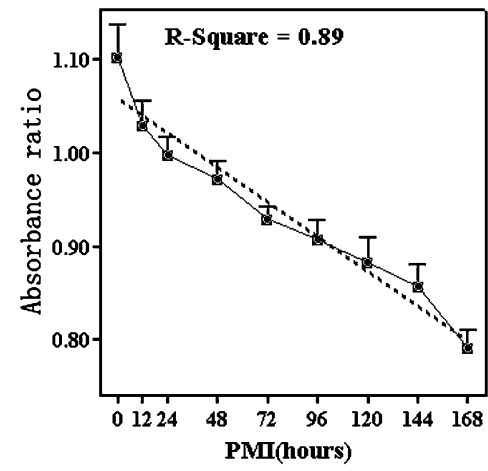

(c)

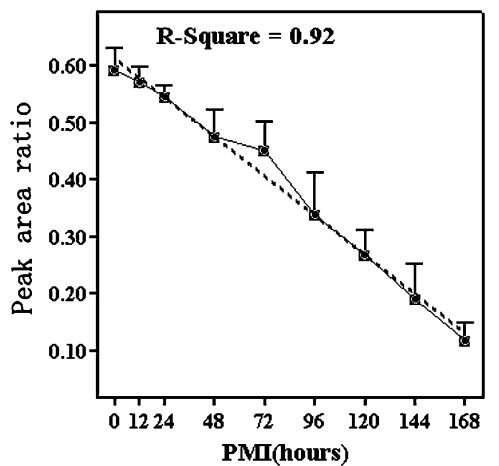

(f)

Fig. 4. Temporal FT-IR spectral intensity ratio of the bands (a) $I_{1652} / I_{1396}$, (b) $I_{1541} / I_{1396}$, (c) $I_{1456} / I_{1396}$. The fitting regression line (- - ) presented linear relationship between intensity ratio and PMI. Temporal FT-IR spectral area ratio of the bands (d) $A_{1652} / A_{1396}$, (e) $A_{1541} / A_{1396}$, (f) $A_{1456} / A_{1396}$. The fitting regression line (- - ) presented linear relationship between area ratio and PMI.

in Fig. 5. $I_{1238} / I_{1396}$ and $I_{1080} / I_{1396}$ ratios showed obvious decreasing linear correlations between intensity ratios and the PMI. Laura et al. [30] show that the postmortem DNA degradation occurs in porcine skeletal muscle from 3 to $56 \mathrm{~h}$ using single cell gel electrophoresis. However, DNA in porcine kidney cannot be detected possibly due to its autolysis. Quantification of mRNA and DNA degradation is closely correlated with the postmortem interval in autopsy cases [14-16]. Our results suggest that the FT-IR spectroscopy can be used to monitor the degradation of nucleic acid up to $168 \mathrm{~h}$ with high efficiency.

The bands at $1338 \mathrm{~cm}^{-1}$ mainly from $\mathrm{CH}_{2}$ wagging stretching of collagen and the bands at $1170 \mathrm{~cm}^{-1}$ mainly from the $\mathrm{C}-\mathrm{O}$ stretching modes of $\mathrm{C}-\mathrm{OH}$ groups of serine, threonine, and tyrosine of proteins [18-20,25] remained the relative stable after death shown in Figs 1(c) and 2. As seen in Fig. 1(c), the band intensity at $1118 \mathrm{~cm}^{-1}$ remained weak and increased slightly from $0 \mathrm{~h}$ to $144 \mathrm{~h}$ after death, but the intensity presented a dramatic increase at $168 \mathrm{~h}$. Some proteins, such as, calmodulin binding protein population remained relative stable for up to $96 \mathrm{~h}$ postmortem in rat muscle and lung. The calmodulin dependent kinase II did not change appreciably over the $96 \mathrm{~h}$ postmortem [13]. Therefore, the further study is needed to examine the absorption bands at 1338, 1170 and $1118 \mathrm{~cm}^{-1}$ as potential markers for estimating long term PMI. In addition, a new band at $1049 \mathrm{~cm}^{-1}$ appeared in some samples after $144 \mathrm{~h}$ postmortem. The 


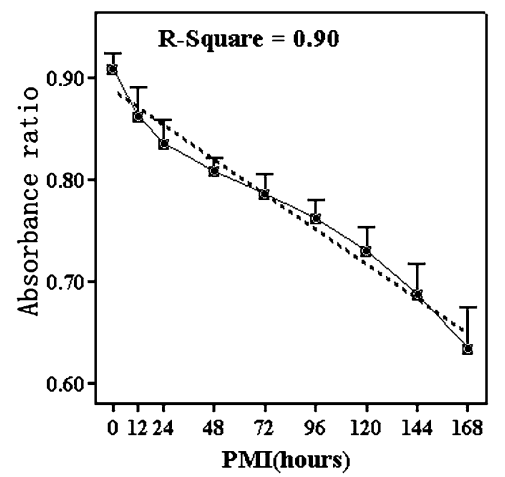

(a)

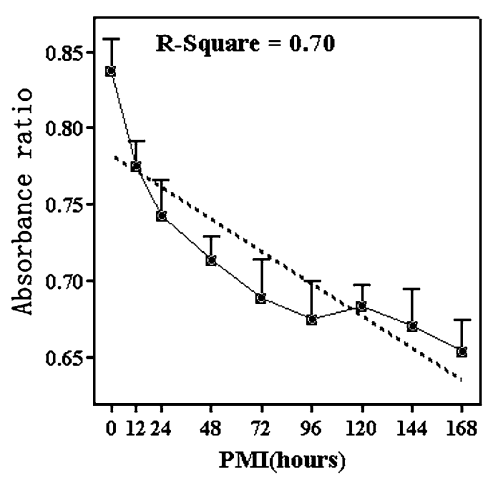

(b)

Fig. 5. Temporal FT-IR spectral intensity ratio of the bands (a) $I_{1238} / I_{1396}$, (b) $I_{1080} / I_{1396}$. The fitting regression line (- - -) presented linear relationship between intensity ratio and PMI.

Table 2

The linear regression equations of different ratios of absorption intensity and area

\begin{tabular}{|c|c|c|c|c|}
\hline Numbers & Linear regression equation & $x$ assignment & $\begin{array}{c}\text { Coefficient of } \\
\text { determination, } R^{2}\end{array}$ & Significance, $p$ \\
\hline 1 & $Y=459.62 x_{1}-235.12$ & $I_{3012} / I_{3303}$ & 0.89 & $<0.01$ \\
\hline 2 & $Y=472.01 x_{2}-289.92$ & $I_{2958} / I_{3303}$ & 0.90 & $<0.01$ \\
\hline 3 & $Y=474.50 x_{3}-330.34$ & $I_{2925} / I_{3303}$ & 0.87 & $<0.01$ \\
\hline 4 & $Y=423.31 x_{4}-182.95$ & $I_{2871} / I_{3303}$ & 0.88 & $<0.01$ \\
\hline 5 & $Y=395.77 x_{5}-175.03$ & $I_{2858} / I_{3303}$ & 0.86 & $<0.01$ \\
\hline 6 & $Y=-117.42 x_{6}+333.10$ & $I_{1652} / I_{1396}$ & 0.83 & $<0.01$ \\
\hline 7 & $Y=-206.12 x_{7}+419.42$ & $I_{1541} / I_{1396}$ & 0.91 & $<0.01$ \\
\hline 8 & $Y=-578.01 x_{8}+619.72$ & $I_{1456} / I_{1396}$ & 0.89 & $<0.01$ \\
\hline 9 & $Y=-14.38 x_{9}+214.30$ & $A_{1652} / A_{1396}$ & 0.94 & $<0.01$ \\
\hline 10 & $Y=-23.84 x_{10}+167.16$ & $A_{1541} / A_{1396}$ & 0.95 & $<0.01$ \\
\hline 11 & $Y=-320.14 x_{11}+202.17$ & $A_{1456} / A_{1396}$ & 0.92 & $<0.01$ \\
\hline 12 & $Y=-632.54 x_{12}+569.14$ & $I_{1238} / I_{1396}$ & 0.90 & $<0.01$ \\
\hline 13 & $Y=-791.61 x_{13}+642.51$ & $I_{1080} / I_{1396}$ & 0.70 & $<0.01$ \\
\hline
\end{tabular}

$Y$ represents postmortem interval, $x$ represents ratio of absorption intensity and area. $I$ : intensity of absorbance band, $A$ : peak area of absorbance band.

appearance of this band may be considered as potential parameters for specific time point postmortem.

\subsection{Analysis of other factors}

There were some overlaps of ratios of absorption intensity and area at some time point postmortem as seen in Figs 3-5. However, regression analysis shows strong correlation between ratios and the PMI. Furthermore, more comprehensive analysis of different ratios will resolve the problem of overlaps. The $20( \pm 2)^{\circ} \mathrm{C}$ was chosen for these experiments in order to approximate a room-temperature environment. As we know, there are many factors that can influence the chemical reactions within tissues after death such as temperature [1]. Moreover, our research group has also monitored the spectral changes of rat kidney cortex at $4^{\circ} \mathrm{C}$ and $30^{\circ} \mathrm{C}$. We found there are similar changes to the $20^{\circ} \mathrm{C}$, and the spectral changes are 
most dramatic at $30^{\circ} \mathrm{C}$ (Fig. 6). These results indicate temperature dependency of postmortem metabolic changes based on FT-IR spectra. Additionally, our research group has also used the FT-IR spectroscopy to study other rat tissues, such as lung, muscle, liver and spleen (Fig. 7), there are similar spectral changes to the kidney cortex, but the spectrum of rat kidney cortex display the most prominent changes

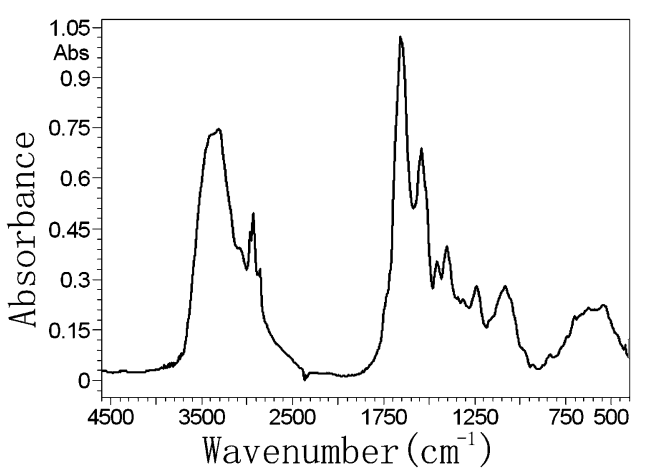

(a)

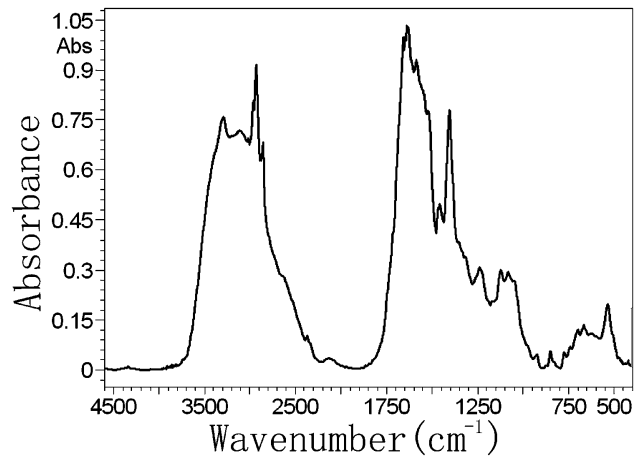

(b)

Fig. 6. FT-IR original spectra of the rat kidney cortex at $4{ }^{\circ} \mathrm{C}$ (a) and $30^{\circ} \mathrm{C}$ (b).

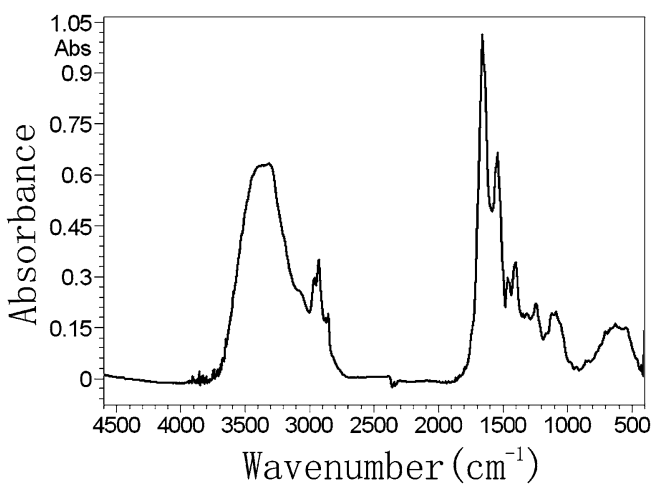

(a)

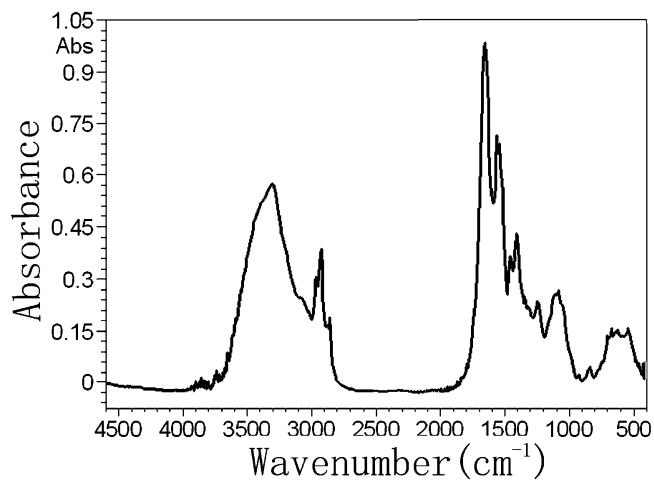

(c)

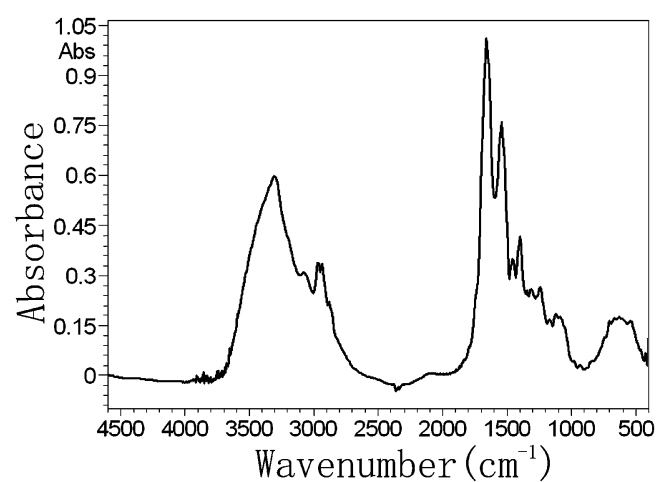

(b)

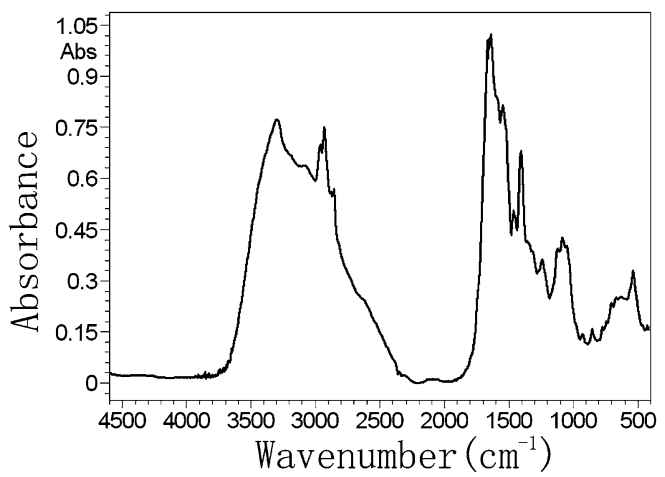

(d)

Fig. 7. FT-IR original spectra of the rat lung (a), muscle (b), liver (c) and spleen (d) at $20^{\circ} \mathrm{C}$. 
than the others. Further studies with human kidney cortex will be needed to verify the utility of the method.

\section{Conclusion}

Our results indicate that FT-IR spectroscopic analysis can monitor the postmortem metabolic changes at molecular level from $0 \mathrm{~h}$ to $168 \mathrm{~h}$ postmortem in rat kidney cortex. There were three different types of metabolic changes after death based on the spectral results: (1) increase continuously (e.g. C-H stretching region); (2) decrease continuously (e.g. $\mathrm{PO}_{2}{ }^{-}$symmetric stretching); (3) remain relatively stable (e.g. $\mathrm{C}-\mathrm{OH}$ bending, $\mathrm{CO}-\mathrm{O}-\mathrm{C}$ asymmetric stretching). The absorption intensity and area ratios show close linear correlations against PMI. Additionally, FT-IR technique is a non-chemical procedure as compared with other bio-molecular methods. Therefore, it has a less influence on the chemical changes within the tissues postmortem. Besides utilizing other classical methods, FT-IR spectroscopy may be a great tool for estimating PMI at the molecular level in the forensic investigations.

\section{Acknowledgments}

The authors would like to thank Dr. Langchong He and Mr. Shaosheng Deng for their kind instruction in FT-IR spectroscopy technique. This study was funded by the Council of National Natural Science Foundation of China (No. 30471935).

\section{References}

[1] B. Knight, Simpson's Forensic Medicine, Oxford University Press, New York, 1996, pp. 20-28.

[2] C. Henssge and B. Madea, Estimation of the time since death, Forensic Sci. Int. 165 (2007), 182-184.

[3] E. Baccino, C. Cattaneo, C. Jouineau, J. Poudoulec and L. Martrille, Cooling rates of the ear and brain in pig heads submerged in water: implications for postmortem interval estimation of cadavers found in still water, Am. J. Forensic Med. Pathol. 28 (2007), 80-85.

[4] K. Honjyo, K. Yonemitsu and S. Tsunenari, Estimation of early postmortem intervals by a multiple regression analysis using rectal temperature and non-temperature based postmortem changes, J. Clin. Forensic Med. 12 (2005), $249-253$.

[5] S. Banaschak, R. Rzanny, J.R. Reichenbach, W.A. Kaiser and A. Klein, Estimation of postmortem metabolic changes in porcine brain tissue using 1H-MR spectroscopy - preliminary results, Int. J. Legal Med. 119 (2005), 77-79.

[6] C. Henssge and B. Madea, Estimation of the time since death in the early post-mortem period, Forensic Sci. Int. 144 (2004), 167-175.

[7] C. Henssge, L. Althaus, J. Bolt, A. Freislederer, H.T. Haffner, C.A. Henssge, B. Hoppe and V. Schneider, Experiences with a compound method for estimating the time since death. I. Rectal temperature nomogram for time since death, Int. J. Legal Med. 113 (2000), 303-319.

[8] N. Lange, S. Swearer and W.Q. Sturner, Human postmortem interval estimation from vitreous potassium: an analysis of original data from six different studies, Forensic Sci. Int. 66 (1994), 159-174.

[9] D. Lucy, R. Aykroyd and M. Pollard, Commentary on J.I. Munoz, J.M. Suarez-Penaranda, X.L. Otero, M.S. RodriguezCalvo, E. Costas, X. Miguens and L. Concheiro. A new perspective in the estimation of postmortem interval (PMI) based on vitreous, J. Forensic Sci. 46 (2001), 1527-1528.

[10] R.A. James, P.A. Hoadley and B.G. Sampson, Determination of postmortem interval by sampling vitreous humour, Am. J. Forensic Med. Pathol. 18 (1997), 158-162.

[11] J.I. Munoz, J.M. Suarez-Penaranda, X.L. Otero, M.S. Rodriguez-Calvo, E. Costas, X. Miguens and L. Concheiro, A new perspective in the estimation of postmortem interval (PMI) based on vitreous, J. Forensic Sci. 46 (2001), 209-214.

[12] A.J. Sabucedo and K.G. Furton, Estimation of postmortem interval using the protein marker cardiac Troponin I, Forensic Sci. Int. 134 (2003), 11-16. 
[13] S. Kang, N. Kassam, M.L. Gauthier and D.H. O’Day, Post-mortem changes in calmodulin binding proteins in muscle and lung, Forensic Sci. Int. 131 (2003), 140-147.

[14] S.J. Cina, Flow cytometric evaluation of DNA degradation: a predictor of postmortem interval?, Am. J. Forensic Med. Pathol. 15 (1994), 300-302.

[15] M. Bauer, S. Polzin and D. Patzelt, Quantification of RNA degradation by semi-quantitative duplex and competitive RTPCR: a possible indicator of the age of bloodstains?, Forensic Sci. Int. 138 (2003), 94-103.

[16] M. Bauer, I. Gramlich, S. Polzin and D. Patzelt, Quantification of mRNA degradation as possible indicator of postmortem interval - a pilot study, Leg. Med. 5 (2003), 220-227.

[17] A. Dogan, K. Ergen, F. Budak and F. Severcan, Evaluation of disseminated candidiasis on an experimental animal model: a Fourier transform infrared study, Appl. Spectrosc. 61 (2007), 199-203.

[18] P.T. Wong, R.K. Wong, T.A. Caputo, T.A. Godwin and B. Rigas, Infrared spectroscopy of exfoliated human cervical cells: evidence of extensive structural changes during carcinogenesis, Proc. Natl. Acad. Sci. USA 88 (1991), 10988-10992.

[19] B. Rigas, S. Morgello, I.S. Goldman and P.T. Wong, Human colorectal cancers display abnormal Fourier-transform infrared spectra, Proc. Natl. Acad. Sci. USA 87 (1990), 8140-8144.

[20] M.A. Cohenford and B. Rigas, Cytologically normal cells from neoplastic cervical samples display extensive structural abnormalities on IR spectroscopy: implications for tumor biology, Proc. Natl. Acad. Sci. USA 95 (1998), 15327-15332.

[21] J. Schuttlefield, H. Al-Hosney, A. Zachariah and V.H. Grassian, Attenuated total reflection fourier transform infrared spectroscopy to investigate water uptake and phase transitions in atmospherically relevant particles, Appl. Spectrosc. 61 (2007), 283-292.

[22] G. Cakmak, I. Togan and F. Severcan, 17Beta-estradiol induced compositional, structural and functional changes in rainbow trout liver, revealed by FT-IR spectroscopy: a comparative study with nonylphenol, Aquat. Toxicol. 77 (2006), 53-63.

[23] F. Severcan, N. Kaptan and B. Turan, Fourier transform infrared spectroscopic studies of diabetic rat hear crude membranes, Spectrosc. - Int. J. 17 (2003), 569-577.

[24] C.J. Thompson, R.G. Riley, J.E. Amonette and P.L. Gassman, Quantification of volatile organics in soil aging experiments using fourier transform infrared spectroscopy, Appl. Spectrosc. 60 (2006), 914-919.

[25] G. Cakmak, I. Togan, C. Uguz and F. Severcan, FT-IR spectroscopic analysis of rainbow trout liver exposed to nonylphenol, Appl. Spectrosc. 57 (2003), 835-841.

[26] B. Stuart, Infrared Spectroscopy: Fundamentals and Applications, John Wiley \& Sons Ltd., West Sussex, 2004, pp. 137-163.

[27] S. Gaudenzi, D. Pozzi, P. Toro, I. Silvestri, S. Morrone and A.C. Castellano, Cell apoptosis specific marker found by Fourier Transform Infrared Spectroscopy, Spectrosc. - Int. J. 17 (2004), 569-577.

[28] N. Toyran, P. Lasch, D. Naumann, B. Turan and F. Severcan, Early alterations in myocardia and vessels of the diabetic rat heart: an FTIR microspectroscopic study, Biochem. J. 397 (2006), 427-436.

[29] F. Severcan, G. Gorgulu, S.T. Gorgulu and T. Guray, Rapid monitoring of diabetes-induced lipid peroxidation by Fourier transform infrared spectroscopy: evidence from rat liver microsomal membranes, Anal. Biochem. 339 (2005), 36-40.

[30] L.A. Johnson and J.A. Ferris, Analysis of postmortem DNA degradation by single-cell gel electrophoresis, Forensic Sci. Int. 126 (2002), 43-47. 


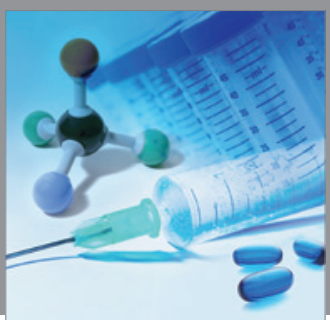

International Journal of

Medicinal Chemistry

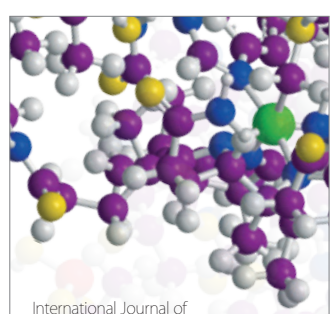

Carbohydrate Chemistry

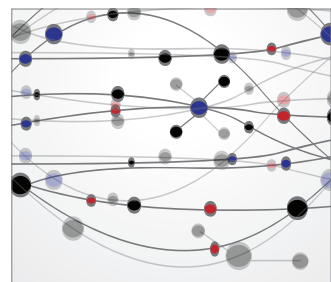

The Scientific World Journal
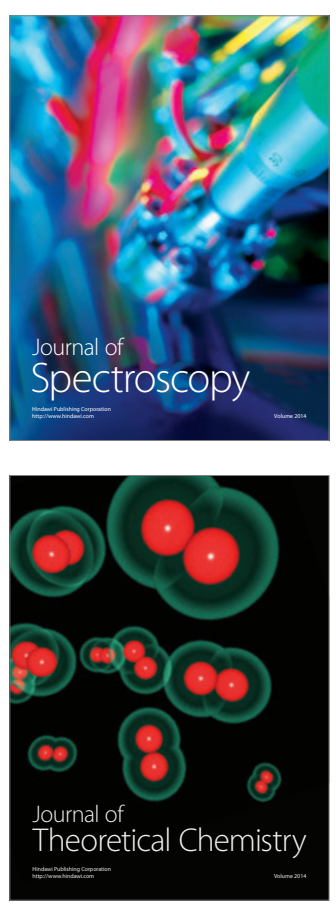
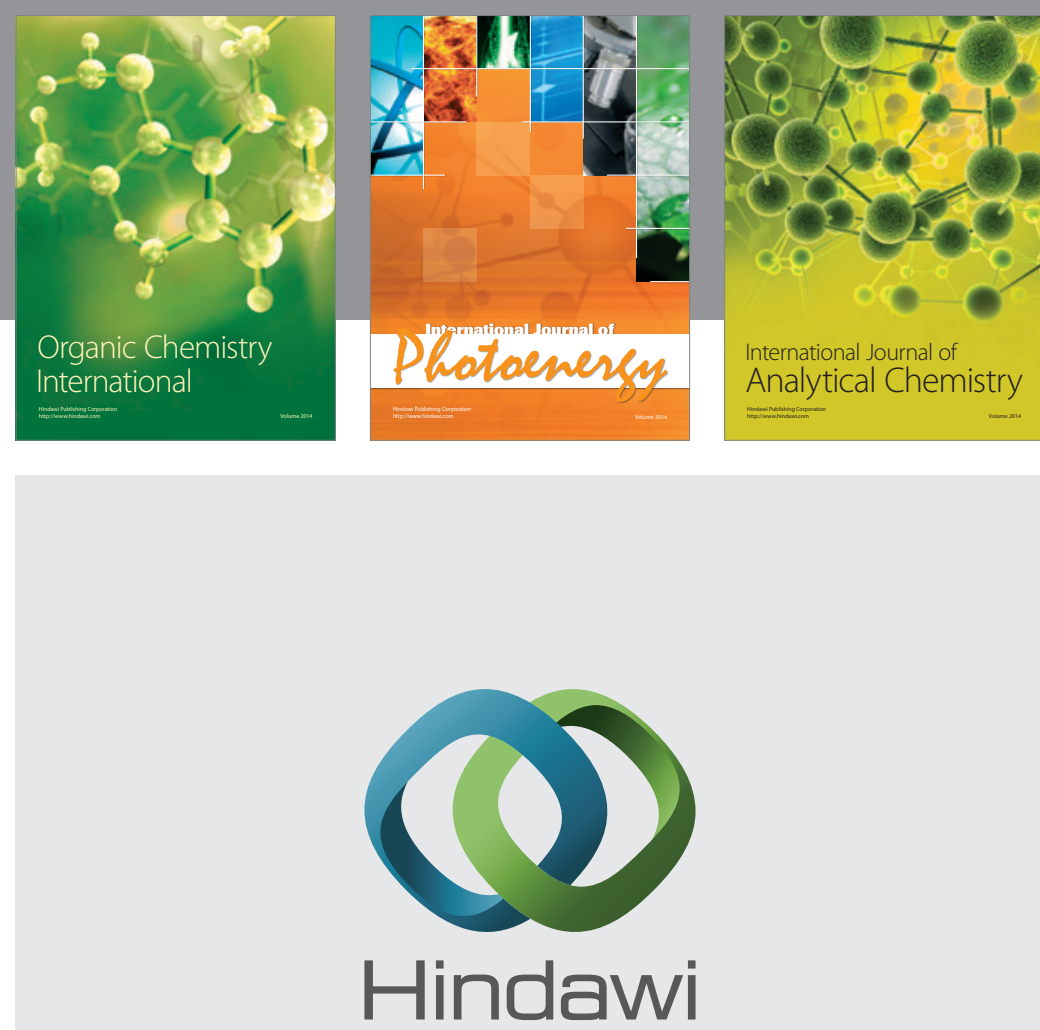

Submit your manuscripts at

http://www.hindawi.com
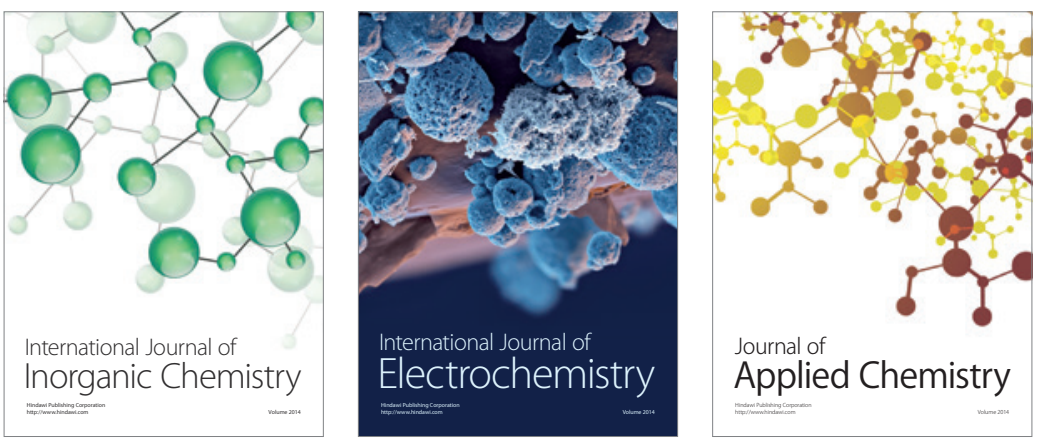

Journal of

Applied Chemistry
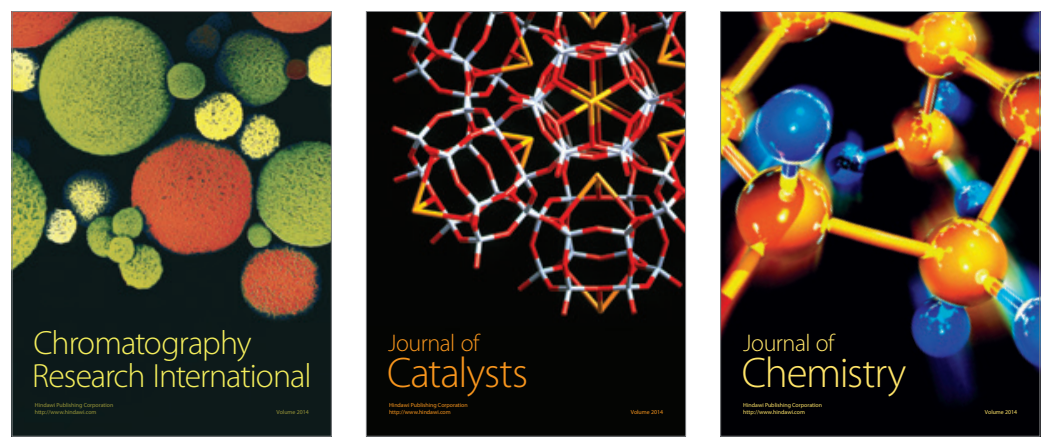
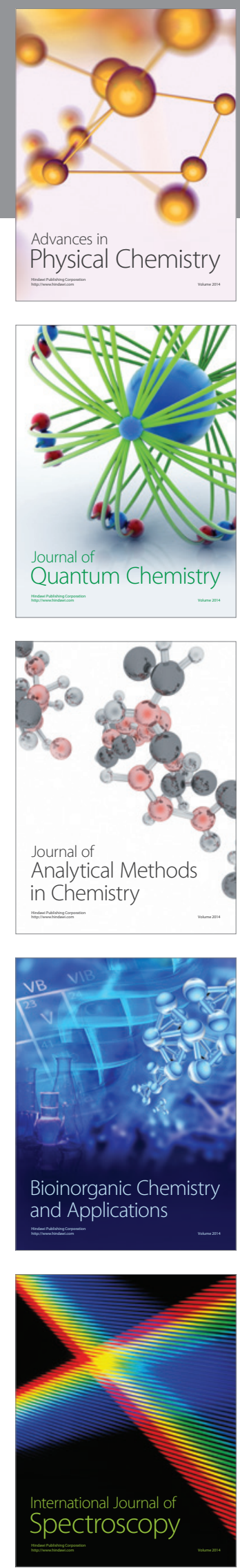